\title{
A REVIEW OF DIFFERENT LEADERSHIP STYLES IN LARGE SIZED INDIAN ORGANIZATIONS IN THE INFRASTRUCTURE SECTOR AND THEIR IMPACT ON ORGANIZATIONAL COMMITMENT
}

\author{
N. SURESH KUMAR ${ }^{1} \&$ DR. SHIKHA KAPOOR ${ }^{2}$ \\ ${ }^{I}$ Research Scholar, Ph. D in Management, Amity University Uttar Pradesh, Noida, India \\ ${ }^{2}$ Professor \& Area Chairperson - HR \& OB, Program Director - Ph.D. Program, Amity International Business School, Amity \\ University Campus, Noida, India
}

\begin{abstract}
Infrastructure sector in India plays a pivotal role in fostering sustainable development of the country. In fact, it plays a crucial role in the core sector of the economy. There has, however, not been a fast paced growth in the infrastructure sector in various parts of the country owing to very many reasons like improper prioritization of this sector in the government planning \& budget allocation, insufficient fund availability, political differences between the ruling party \& opposition parties, problems in land acquisition, bureaucracy, corruption. Organizations in the space of infrastructure, however, once commence \& continue work apart from issues of dealing with Govt bodies, locals, regulatory \& taxation issues, financial management need to have effective leadership within their organizations to deliver the objectives that they have set forth. This research aims to review leadership styles in large sized Indian organizations in the infrastructure sector and to examine the impact of different leadership styles on organizational commitment as commitment to the organization or the concerned business entity, can be a great differentiator in achievement of the business and societal goals of the organization. 159 respondents from the Indian Public and Private sector companies in the infrastructure sector were surveyed using a structured questionnaire. These respondents belong to different role bands or strata of management. The data was analyzed using descriptive and inferential tools. Findings from the research show that among the five organizations, transformational leadership style is followed by most of the organizations as employee participation in the decision making process is considered important and though final decision rest on leaders but still the organization is open to the suggestions of employees. Results shows that though transformational and transactional leadership style along with employee empowerment and organizational citizenship behavior has significant impact on the organizational commitment but still major factor which contributes in boosting the commitment level of employees is transformational leadership style. Thus, leaders in close involvement and association with the employees should work on handling the challenges borne by the infrastructure sector by considering the suggestion of employees. It should overcome the business and people problems in order to contribute towards the sustainable growth of the country.

KEYWORDS: Leadership Style, Organizational Commitment, Transactional Leadership, Transformational Leadership Style.
\end{abstract}

Received: Jun 09, 2020; Accepted: Jun 29, 2020; Published: Aug 06, 2020; Paper Id.: IJMPERDJUN2020650

\section{INTRODUCTION}

Leadership Style and Organizational Commitment of Employees

In the current corporate world, leadership has become one of the key factors for the success of the organizations. The increasing importance of leadership is because leadership is responsible for the integration and the 
harmonization of both the resources and the human assets which combines to produce the final output or services (Kraus $\&$ Wilson, 2012; Mester, Roodt, \& Kellerman, 2003).

There is no unique definition for leadership; various authors have defined leadership in various ways however there is a common understanding - that leadership is a process which involves influencing others commitment towards realizing the full potential in achieving the value added, passion, shared vision and also integrality. One of the important aspect of the leadership is the relationship between the leader and the individual followers (Kehinde \& Banjo, 2014).

The effect of commitment of employees, i.e., called 'organizational commitment' in the parlance of organizational behavior discipline varies according to the leadership style practiced in the organizations. On one hand, Transformational Leadership motivates the employees to perform beyond their expectation (Hater \& Bass, 1988).Scholars of the transformational leadership suspects that the this type of leadership may lead to the emotional attachment of the leader and the followers (Bass \& Avolio, 1997).On the other hand, the transactional leaderships mainly based on the bureaucratic authority, tradition and legitimacy where the followers get certain outcomes when they work according to the leader's wish.(Hartog \& Hartog, 1997)) .

\section{Importance of Organizational Commitment}

The performance of the employees plays an important role in the success of the organization and the employee commitment towards the organization is one of the main determinants for the organizations' performance. So the commitment of the employees has emerged as one of the crucial work attitude studies among the scholars (Irefin \& Mechanic, 2014). Employees who are highly motivated contribute both energy and time to attain the organizational goals and also provide the intellectual capital which is considered to be the critical assets for any organization (Hunjra, Chani, \& Azam, 2010).

\section{India's Infrastructure Sector}

Infrastructure sector in India works as the backbone for the country wherein by fostering the process of development, it leads to overall growth of the economy. During the period of $10^{\text {th }}$ and $11^{\text {th }}$ Five Year Plans, it has been identified that poor infrastructure facilities are the significant barriers in the growth of Indian economy(IBEF, 2013). As a result, the Government of India initiated various efforts like Public-Private Partnerships (PPP) for directing the private investments into the infrastructure sector. There has been raise of investment from $4.7 \%$ of GDP to $7.5-8 \%$ in the $11^{\text {th }}$ five-year plan. Though there has been doubling in investment from INR 20.5 trillion to 40.9 trillion in $12^{\text {th }}$ Five Year Plan but still the having the major share of investment in the oil \& gas and telecom sectors lead to shortfall for railways, roads, and ports(Solanki, 2016). Covering up this investment backlog, infrastructure sector has witnesses an upward trend of growth i.e. with power consumption of $1149 \mathrm{kWh}$ in India power generation capacity increased to $344 \mathrm{GW}$, network of roads has grown at $3.7 \%$ CAGR rate, and railway route expansion is at $0.25 \%$ per annum. However, issues like lack of risk management and upfront planning, uncertainties in regulatory approvals and land acquisition process, non-collaboration among stakeholders, scarcity of skilled labour and mainly the poor project management process are hampering the adequate functioning of the infrastructure sector (MoSPI, 2019).

Leadership helps in providing cohesiveness, contentment among subordinates, and building environment for creativity and innovation. Apart from efficient delivery of public services, the leadership also coordinates the fundamental operations of the sector in order to handle the technical problems(Gita, 2014; Gqaji et al., 2016). The infrastructure sector 
faces the problem of disparity in rural and urban areas along with non-availability of sufficient facilities to meeting the infrastructural needs of population. Effective leadership not only helps manage the functioning but also would address the issue of disparity in development by improving the capacity. Further, the problem of accountability and lack of transparency in the Indian infrastructure prevent the infrastructure sector from meeting the consumption needs of people, thus leadership would regulate the delivery of facilities to the consumer and help in building up a transparent, accountable, and more responsive environment leading to sustainable contribution in the development of economy (Ekene \& Ugwunwanyi, 2016; MoSPI, 2019).

\section{AIM OF THE STUDY}

This research is aimed to review the leadership styles in large sized Indian organizations in the infrastructure sector(both in public sector and private sector) and examine the impact of the leadership on organizational commitment. For the purpose of this research paper, large sized Indian Organizations in the infrastructure sector have been taken those as employing over 3000 nos. on direct rolls of the organization and excludes those engaged through outsourced rolls.

\section{LITERATURE REVIEW}

\section{Importance of Leadership in Large Sized Organizations}

Leadership as a process and concept has been much talked about in the world of management. There are various theories on leadership starting from the emphasis on personality traits, qualities of leaders, nature and tendency of control, task orientation, and people relatedness to contingency based theory. As this research is aimed at leadership styles, review of literature pertaining to leadership theories is not done. According to John Gardner, in "On Leadership", "Leadership is the process of persuasion or example by which an individual (or leadership team) induces a group to pursue objectives held by the leader or shared by the leader and his or her followers." If leadership is the process then leadership style is the way in which the process of leadership is carried out. How does a leader go ahead in dealing with his or her followers to accomplish set of tasks on hand, how does he/she deal and maintain relationship with his/her team members, how does the leader cope or interact or face the various challenges within ,outside the group or organization. All such nature of interactions of the leader is collectively referred to "leadership styles". Various authors and researchers starting from the 1930s by Kurt Lewin have dealt at length about the type of leadership styles. He argued that there are three major types of leadership, viz., Autocratic, Democratic and Laissez-faire. Daniel Goleman, Richard Boyatzis, and Annie Mckee detailed six emotional leadership styles in their 2002 book "Primal leadership". They categorized in their theory, six styles, viz., Visionary, Democratic, Coaching, Affiliative, Pacesetting, and Commanding. It talks of how each style affects the emotions of team members and followers. One of the most prominent formats for classifying and studying leadership includes three styles - transformational, transactional and laissez-faire leadership. In this approach, leadership is conceptualized by the behavioral areas from laissez-faire -style (non-leadership), through transactional leadership (which hinges on reward system and punishment), to transformational leadership (which is based on inspiration and behaviouralcharisma) (Bass and Avolio, 1993). These three styles are chosen in this research paper because of the effectiveness proved time and again in the management field in attaining organizational results depending on the context and circumstances. A little elaboration of these three styles is as follows:

Laissez-faire: The term Laissez-faireoriginates from a French word which means "to leave alone". In this style, the leader totally shun his or her responsibility either towards the outcome or in exercising any kind of control over the 
tasks or the subordinates and is not involved in any manner in the accomplishment of results. He or she may, however, be interested remotely in partaking the results of the efforts rendered by the members.

Transactional Style: As the name suggests, it primarily fulcrums on transaction of relationship and rewards between the leader and team members. "Using a carrot or a stick, transactional leadership is usually characterized as instrumental in followers' goal attainment” (Bass, 1997). There are three constituents in transactional style - 'contingent reward' whereby relationship between team members and leaders is based on contingent rewards or exchange relationships; 'Active Management by exception' wherein leaders keep a watch on team members performance and if there are deviations or fall outs then they take immediate correction action \&Management by thirdly 'Passive exception' in which leaders distance from the routine matters and intervene only problems arise.

Transformational: This is a much evolved style in which the leader is a change agent, inspirational lighthouse. The team members look upon the leader as a source of admiration, trust, a pathfinder, a visionary, a champion of problem solving. In this style, the leader believes in energizing his/her team members, followers through setting a purpose and attempts to intrinsically motivate them rather than through any external reward or purpose.

In the current globalized and competitive world, it has become difficult to handle the employees who have different background in terms of culture, ethics, and psychology (Albion \& Gagliardi, 2007). A good leadership helps to influence people to perform the tasks more willingly, competently and willingly. Similarly, in the large organization the harnessing of the ideas, energy, skills and the enthusiasm of all the employees is required for the success and only a good leadership can achieve those goals (Hater \& Bass, 1988).

\section{Common Leadership Strategies in Large Scale Organizations}

The long term success of any organization depends on the leadership culture and also the continuous development of leadership across all the levels. In the current competitive world, the success of the large sized organization is largely driven by the leadership strategy and style which have a bearing on the organizational performance. In many large organizations, the main focus is mainly on building the leadership development which helps to support, train and select the potential personnel who are able to drive the business's strategy (Fairholm, 2009).

Different organizations adopt different leadership practices and styles for the success of their business. All these practices and styles have an impact on the organizational culture. Organizational culture in the large organizations focus on creating the favorable working condition and knock out the negativity and fear from the employees and regroup, and unite the employees to make winning culture among the teams (Pasmore, 2014). Some of the big organizations focus on enhancing the cross culture' relationship — building through various training and skill development programs among the leaders. Greater dependence on the leaders for the creation of more effective collaboration across various departments is one of the common leadership strategy followed by many large companies (Pasmore, 2014).

\section{Factors Affecting Organizational Commitment}

Organizational Commitment of the employees have significant impact on the performance of the employees and hence on the overall performance of the organization. Various factors play an important role in determining the organizational commitment (Albdour \& Altarawneh, 2014). Commitment is a sense of binding or attachment towards something on account of some reason. There is a reason to believe that people need to be committed to something with the opposite of commitment being Alienation or Indifference. Perhaps, one of the most thoroughly investigated approach to organizational 
commitment is the perspective advanced by Mowday and his colleagues, which emphasizes the employee's affective bond with the organization (Mowday, Porter, \& Steers, 1982). This viewpoint asserts that organizational commitment is characterized by (a)" a strong belief in and acceptance of the organization's goals and values; (b) a willingness to exert considerable effort on behalf of the organization; and $\{c)$ a strong desire to maintain membership in the organization.

According to Gross and Etzioni (1985), three different classifications of organizational value orientation are possible. Coercive organizations use physical threats to control employee behaviour, whereas utilitarian organizations use material rewards (e.g., salary increases) to influence employees. Normative organizations manipulate symbolic rewards to guide employees, and allow for the largest degree of employee involvement.

With various researchers giving conceptualization of Commitment, one set of definition or explanation of Commitment in the Organizational Context, which stands out from others is that of the researchers, John P. Meyer\& Natalie J. Allen (in 1991), \& terming it as Organizational Commitment. Meyer and Allen have noted that common to the various definitions of organizational commitment is "the view that it is a psychological state that (a) characterizes the employee's relationship with the organization, and (b) has implications for the decision to continue membership in the organization.

Meyer and Allen proposed a Three-Component Model of Commitment terming Affective, Continuance and the third as Normative Commitments. Meyer and Allen argued that it was more appropriate to consider continuance, and affective, normative commitment to be components, rather than types, of commitment because an employee's relationship with an organization might reflect varying degrees of all three.

Affective Commitment refers to the employee's emotional attachment to, identification with, and involvement in the organization. Continuance Commitment refers to an awareness of the costs associated with leaving the organization. Normative Commitment reflects a feeling of obligation to continue employment.

Some of the factors which influence organizational commitments, as per various researchers are as follows:-

- Organizational Citizenship Behaviour: The organizational citizenship behavior refers to the discretionary performance of the job where the employee can go beyond the defined job requirements and also develop helping behavior towards the other employees (Organ, 1988).Employee-organizational citizenship behavior is positively related to the organizational commitment of the employee in the organization. (Allen \&Rush, 1998; Cappelli \& Rogovsky, 1998; Organ, 1988). Citizenship behavior means those attributes in an employee which makes him being more considerate than others and this type of behavior, though not formally laid down specifically by organizations (Koster \& Sanders, 2006) but are expected and desirable as this type of behavior leads to innovation and resource transformation and adaptability of the employee which thus contributes for the betterment of the organization (Turnipseed \& Murkison, 1996). Allen \& Meyer (1990) believe that organizational citizenship behaviour tend to appear more with affective commitment, who show a behavior critical to organizational success than people having normative or continuance commitment. But overall it is seen that organizational commitment is not always related to performance or productivity (Becker \& Billings, 1993), though sometimes some patterns of influence these commitments do variables.

- Employee Empowerment: Empowerment is a motivational practice that aims to raise the performance capacity of employee by encouraging involvement and participation in the decision making process of organizations. It 
includes assignment of authority and responsibility to employees, involving employees in decision making, and creating condition for building up mutual trust between employees and management(Hanaysha, 2016; Insan et al., 2013). Influencing feelings like meaningfulness, competency, effectiveness, autonomy, and trust; empowerment tends to create positive attitude in employees and motivate them to perform best at their workplace. As empowerment is actually the sharing of the top level management powers with the lower level employees, it works as a motivational technique to boost up the satisfaction level(Anne Kariuki \& Kellen Kiambati, 2017; Zaraket et al., 2018). Active involvement in the decision making process and job satisfaction makes the workforce more committed and even play their role in the success and effectiveness. In order to gain a competitive advantage it is essential that organizations respond quickly to changes in consumer demand and business environment. But, this could only be possible with the availability of the empowered employee(Khan et al., 2014). Though the existence of empowerment would also leads to negative influence on the continuance commitment of employees as psychologically empowered would search for employability and alternatives outside the current organization but still majorly, there is improvement in the capability and productivity of the employees with this motivational psychological development of employees(Singh, 2017).

- Leadership style: Leadership style defines the behaviour used by the leader in order to influence the attitude and behaviour of employees along with resolving the organizational issues. Stating the values, beliefs, norms, and ideas of leader; the leadership style can be majorly categorized into three forms i.e. transformational leadership, transactional leadership, and laissez-faire leadership. The style of leadership adopted by an organization has an impact on the commitment level of employees(Shin, 2013). Public sector emphasizes on flexibility and adaptation level, therefore the right leadership style increases organizational commitment level. With focus on the 4 attributes i.e. intellectual stimulation, idealized influence, individualized consideration, and inspirational motivation; the transformational leadership is considered to be having positive and strong impact on organizational commitment level while with the focus on the contingent reward and management by exception, the transactional leadership style affects organizational commitment (Sohail et al., 2015). Further, studying the impact of leadership style on different commitment defines that affective and normative commitment of an employee is affected by the choice of leadership style but the continuance commitment does have a significant linkage with the style. Transformational leadership style encourages the employees and gives them the means to have the critical thinking about various organizational issues. This enhancement not only motivates the employees but also strengthen their trust on the organization hence affecting the commitment level. Thus, the choice of the effective leadership style is an important antecedent of the organizational commitment level of employees(Anderson, 2015).

\section{METHODOLOGY}

This research is aimed to identify the various leadership styles in the large sized Organizations in the Indian infrastructure sector and examine the impact of the leadership style on the commitment of organizational employees. A primary research has been carried out by way of administering an objective, multiple-choice, closed ended questionnaire to the white collar workforce of a five large sized Indian infrastructure organizations, viz., which each of them individually employ over3000 numbers of regular / on roll employees. These organizations are in the Public Sector and Private Sector. For reasons of privacy, names of these organizations are not disclosed. In total, data from 159respondents have been collected (approx. 
32 from each organization). Below stated hypothesis is framed for examining the leadership style impact on organizational commitment i.e.

- $\mathrm{H}_{0}$ : There is no significant impact of leadership style on organizational commitment of employees.

- $\mathrm{H}_{\mathrm{A}}$ : There is a significant impact of leadership style on organizational commitment level of employees.

To analyze the data, descriptive quantitative research survey method has been followed and correlation and regression analysis has been performed to find the impact of the leadership style on the organizational commitment of the employees at 5\% level of significance. The data has been analyzed using the statistical software SPSS 21.

\section{ANALYSIS}

In order to understand the implication of the leadership style in the Indian infrastructure sector and to determine the impact of different leadership style on the organizational commitment level, the examination of the perception and experience of about 159 employees is done. The analysis of the demographic characteristics of the respondents, their knowledge about the leadership style, and the impact analysis is shown in the below stated sub-sections.

\section{Demographic Analysis}

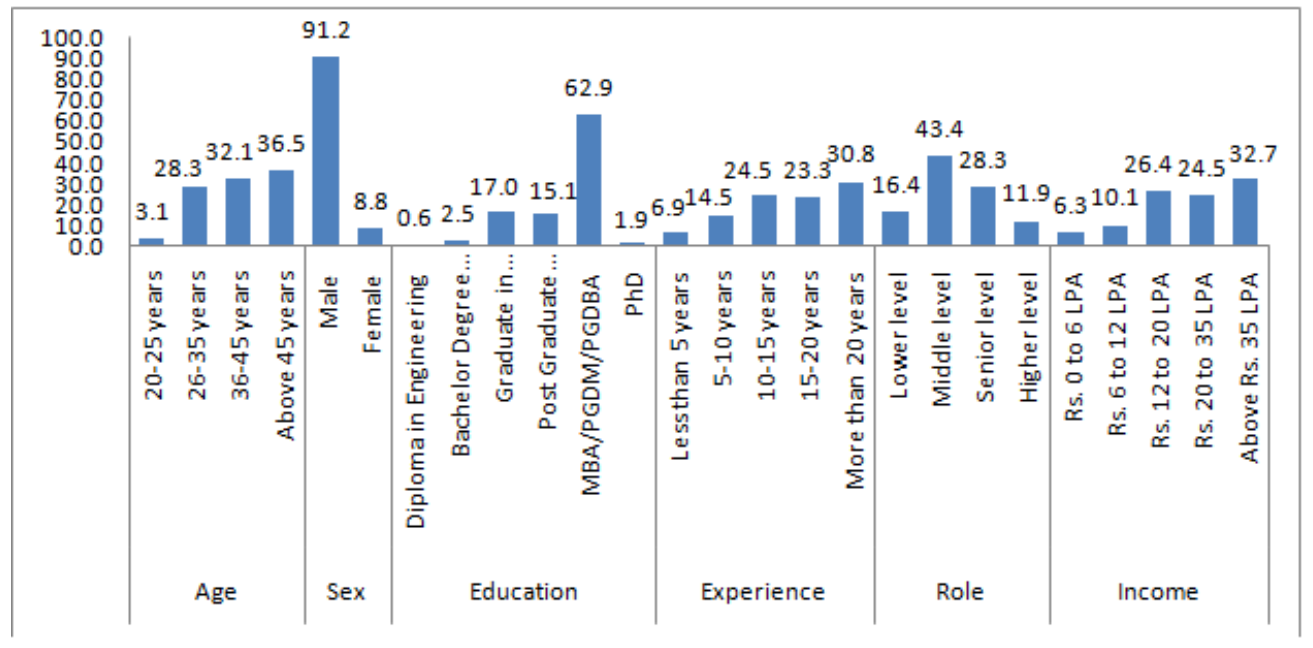

Figure 1: Demographic Analysis.

Above graph shows that among the 159 respondents, about 3.1\% of the employees is from age-group 20-25 years, $28.3 \%$ of them belong to age-group $26-35$ years, $32.1 \%$ of them are from age group of 36-45 years, and remaining $36.5 \%$ employees are of age above 45 years. Among the total respondents of the study, 91.2\% of them are male while remaining only $8.8 \%$ of employees are female. Education level of the employees further shows that $0.6 \%$ of employees have done diploma in engineering, $2.5 \%$ of them have bachelors degree in $\mathrm{BA} / \mathrm{BCom} / \mathrm{BSc}, 17 \%$ of employees hold graduation degree in engineering (BE/BTech), $15.1 \%$ of the employees have completed their post graduation (MA/MCom/MSc), most of the employees i.e. $62.9 \%$ have MBA/PGDM/PGDBA degree, and remaining $1.9 \%$ of the employees hold PhD degree. Work experience of employees depicts that about $6.9 \%$ of the employee have less than 5 years of experience, $14.5 \%$ of the employees have work experience of about 5-10 years, 24.5\% of them have 10-15 years of experience, $23.3 \%$ of the employees have 15-20 years of experience, and remaining 30.8\% of the employees experience is more than 20 years. Role of respondent's further shows that about $16.4 \%$ of them have lower level management role, $43.4 \%$ of employees have middle level management role, $28.3 \%$ of employees have senior level management role, and remaining $11.9 \%$ of 
employees are working at higher level management. Income level further shows that $6.3 \%$ of respondents have annual income upto Rs.6 lakhs, $10.1 \%$ of them have monthly income between Rs. 6 - 12 lakhs, 26.4\% of them have annual income ranging between Rs. 12-20 lakhs, $24.5 \%$ of employees have income ranging between Rs. 20-35 lakhs, and remaining about $32.7 \%$ of them have annual income above Rs. 35 lakhs. Thus, demographic analysis of the respondents show that most of the employees considered for the study male employees having age above 36 years holding management degree with experience of greater than 10 years and working at middle level management with annual income of above Rs.12 lakhs.

\section{Leadership Style in Organization}

Background profile defines the examination of the respondent's knowledge about the leadership style of their organization. Frequency based analysis of the responses is shown in below figure:

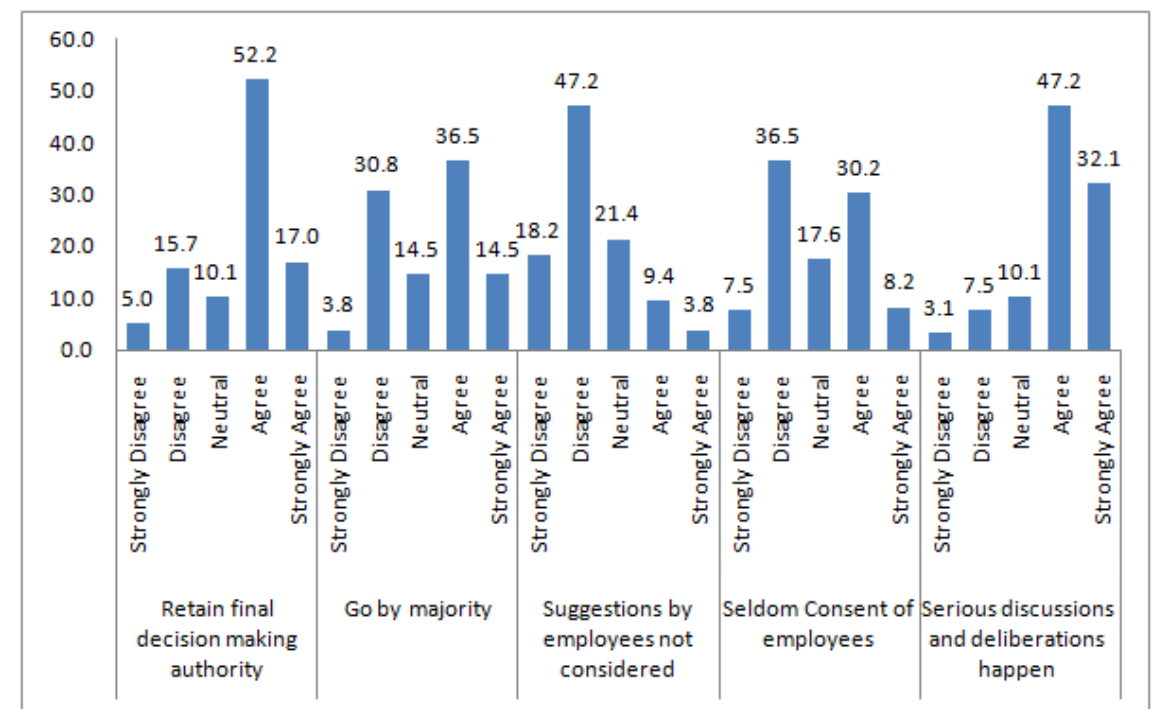

Figure 2: Background Analysis.

Above figure shows that $20.7 \%$ of the employee denies the presence of final decision make authority within their department or team while about $69.2 \%$ of employees agree that leaders in their organization maintain a decision making authority. $33.8 \%$ of respondents denied the process of going by majority for any decision in business while $51 \%$ of the employee accepted that their organization leaders follow the process of making any major decision regarding the business or function based on the majority. With regard to having no consideration of employee's suggestions, about $65.4 \%$ of respondents stated that their organization does value the employee suggestions and consider them for decision making while about $13.2 \%$ of employee accepted that their organization leaders doesn't consider employee's suggestions. For the seldom consent of employees in major decisions of department, about $44 \%$ of the respondents denied having only seldom consent in major decision while $38.4 \%$ of employee accepted having consent from them only in seldom decisions. Further, about $10.6 \%$ of respondents denied having serious discussions and deliberations before any vital decision of organization while about $79.3 \%$ of employee's accepted that before having any vital decision in organization, their leaders are open to serious discussions and deliberations. 


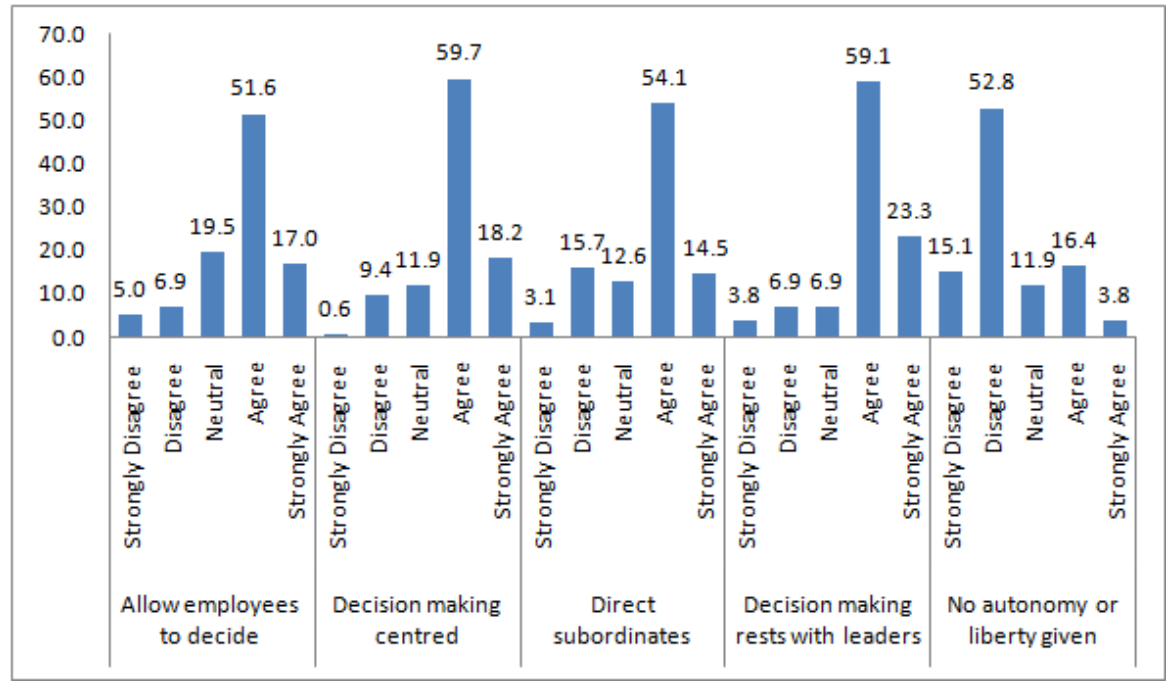

Figure 1: Background Analysis.

About $11.9 \%$ of respondents denied having the freedom to take any decision for handling the challenges in their job and resolving them while $68.6 \%$ of the employees accepted that their organization allow them to make decisions for handling challenges. With respect to the decision making centralization, about $10 \%$ of employees denied that their decision making is not centered at certain level while $77.9 \%$ of respondents accepted that their organization follow the mechanism of centralizing the decision making process at certain level. About direction by leaders, about $18.8 \%$ of employee's stated that leaders in organization does not use their authority for directing subordinates but about $68.6 \%$ of respondents accepted having the direction from leaders. Further, about consultation with employees but having the entire decision making process rested on leaders, about $10.7 \%$ of respondents denied having such leadership style in their organization while about $82.4 \%$ of employee accepted that though while making any decision leaders in their organization consult them befor any decision but majorly the final decision making entirely rest on leaders. Lastly, about having no liberty to employee, about $67.9 \%$ of respondents denied this aspect while $20.2 \%$ accepted that no autonomy or liberty is available to employees or subordinates in executing their job. Hence, the analysis of the leadership style in organization suggest that employees participation is considered important for the decision making process, and though the entire decision is rested on the leaders but still value is given to the autonomy and suggestions of employees.

\section{Factors which Impact Organizational Commitment}

Based on the review of the factors having impact on the organizational commitment level, it has been identified that there are mainly three things i.e. employee empowerment, organizational citizenship behavior and the leadership style which contribute in influencing the commitment level of employees. As the review suggests that laissez faire style doesn't have significant influence on affecting the commitment level of employees, thus, based on this aspect, this section empirically examines the contribution of the two different leadership style (transformational and transactional) in influencing the organizational commitment level in presence of employee empowerment and organizational citizenship behavior. In order to have the impact analysis, the statements for representing each of the factor is coded and the average value of the statements depicting organizational commitment is determined. Coding of the variables is shown in below table. 


\begin{tabular}{|c|c|}
\hline \multicolumn{2}{|l|}{ Table 1: Coding for Variables } \\
\hline Statements & Code \\
\hline \multicolumn{2}{|l|}{ Transformational Leadership } \\
\hline Leaders are always seeking new opportunities for the unit/department/organization. & TF1 \\
\hline Leaders lead by doing rather than simply by telling. & TF2 \\
\hline Leaders encourage employees work as a team rather than as separate individuals. & TF3 \\
\hline \multicolumn{2}{|l|}{ Transactional Leadership } \\
\hline Leaders give employees special recognition for good work & T1 \\
\hline Leaders commends when employees do a better than average job. & $\mathrm{T} 2$ \\
\hline \multicolumn{2}{|l|}{ Employee Empowerment } \\
\hline Employees feel capable enough to perform the tasks required for their position & EE1 \\
\hline Employees are self-assured about their capabilities to perform their work activities & EE2 \\
\hline Employees have the authority to make the decisions that need to be made to perform their job well & EE3 \\
\hline Employees have considerable opportunity for independence and freedom in how they do their job. & EE4 \\
\hline \multicolumn{2}{|l|}{ Organizational Citizenship Behavior } \\
\hline $\begin{array}{l}\text { Employees help other employees to learn new skills or share job knowledge in order to promote } \\
\text { 'we'feeling. }\end{array}$ & OCB1 \\
\hline Employees offer suggestions to one another to improve how work is done & OCB2 \\
\hline Employees say good things about the employer in front of others & OCB3 \\
\hline \multicolumn{2}{|l|}{ Organizational Commitment } \\
\hline Average & $\mathrm{OC}$ \\
\hline
\end{tabular}

In order to determine whether there is any relationship between the organizational commitment and the independent factors (leadership style, employee empowerment, and organizational citizenship behavior) Karl Pearson Correlation analysis is done. A result of the examination is shown in below table.

Table 2: Correlation Analysis

\begin{tabular}{|c|c|c|}
\hline Dependent Variable & \multicolumn{2}{|c|}{ OC } \\
\hline Statements & Pearson Correlation & Sig. (2-tailed) \\
\hline OC & 1 & \\
\hline TF1 & 0.587 & .000 \\
\hline TF2 & 0.663 & .000 \\
\hline TF3 & 0.606 & .000 \\
\hline T1 & 0.622 & .000 \\
\hline T2 & 0.535 & .000 \\
\hline EE1 & 0.552 & .000 \\
\hline EE2 & 0.697 & .000 \\
\hline EE3 & 0.491 & .000 \\
\hline EE4 & 0.565 & .000 \\
\hline OCB1 & 0.552 & .000 \\
\hline OCB2 & 0.542 & .000 \\
\hline OCB3 & 0.536 & .000 \\
\hline
\end{tabular}

The significance value in the above table shows that for each variable the sig level is 0.000 which is less than the required significance level of 0.05 . Thus, each variable is significant enough to represent their linkage with other variables and there is a possibility to have a relationship between variables. Pearson coefficient shows that for each statement the value is greater than 0.5 except for EE3 which is 0.491 (TFI - 0.587, TF2 -0.663, TF3-0.606, T1-0.622, T2-0.535, EE10.552, EE2-0.697, EE4-0.565, OCB1-0.552, OCB2-O.542, and OCB3-0.536). Hence, there is presence of significant and positive linkage between the variables and as EE3 is less than 0.5 thus it is not considered for further analysis. 


\section{Impact of Different Leadership Styles on Organizational Commitment}

In order to determine the impact of different leadership style for the identified significant variables, the regression analysis would be done. Herein, considering the organizational commitment as the dependent variable, influence of different leadership i.e. transformational and transactional leadership style is determined in presence of employee empowerment and organizational citizenship behavior as other independent variables. A result of the analysis is shown in below table.

Table 3: Effect of Transformational Leadership Style on Organizational Commitment

\begin{tabular}{|c|c|c|c|c|c|c|}
\hline OC & Coefficient & T-statistic & p-value & $\mathbf{R}^{\mathbf{2}}$ & Adjusted R $^{2}$ & F ratio \\
\hline Constant & -0.53 & -2.68 & 0.01 & 0.76 & 0.74 & 51.82 \\
\hline TF1 & 0.16 & 3.47 & 0.00 & & & \\
\hline TF2 & 0.36 & 4.95 & 0.00 & & & \\
\hline TF3 & 0.06 & 1.29 & 0.20 & & & \\
\hline EE1 & 0.00 & 0.02 & 0.98 & & & \\
\hline EE2 & 0.30 & 5.82 & 0.00 & & & \\
\hline EE4 & 0.00 & 0.02 & 0.98 & & & \\
\hline OCB1 & 0.00 & -0.01 & 0.99 & & & \\
\hline OCB2 & 0.15 & 2.61 & 0.01 & & & \\
\hline OCB3 & 0.07 & 1.52 & 0.13 & & & \\
\hline
\end{tabular}

Herein for the transformational leadership, the value of $\mathrm{R}^{2}$ and Adjusted $\mathrm{R}^{2}$ is 0.76 and 0.74 . Adjusted $\mathrm{R}^{2}$ shows that about $74 \%$ of the variation in the organizational commitment is represented by transformational leadership style, employee empowerment, and organizational citizenship behavior. F-ratio value of 51.82 is greater than the required value of 1 depicting that more precision is derived in computation of organizational commitment by adding transformational leadership, employee empowerment, and organizational citizenship behavior as independent variables. P-value of all the statements further shows that for TF1 (0.00), TF2 (0.00), EE2 (0.00) and OCB2 (0.01) the value is less than the significance level of the study. i.e. 0.05. Thus, the null hypothesis of having no significant impact of antecedents on the organizational commitment level of employees is rejected. Coefficient level further shows that about $1 \%$ increase in TF1 (Leaders seeking new opportunities), TF2 (leader lead by doing), EE2 (self-assured employees), and OCB2 (suggestion offering by employees to one another) leads to rise in the commitment level of employees by $0.16 \%, 0.36 \%, 0.30 \%$, and $0.15 \%$ respectively.

The results for assessing the impact of transactional leadership style on organizational commitment level is shown in below table

Table 4: Effect of Transactional Leadership Style on Organizational Commitment

\begin{tabular}{|c|c|c|c|c|c|c|}
\hline OC & Coefficient & T-statistic & $\mathbf{p}$-value & $\mathbf{R}^{\mathbf{2}}$ & Adjusted $^{\mathbf{2}}$ & F ratio \\
\hline Constant & -0.14 & -0.69 & 0.49 & 0.71 & 0.70 & 46.60 \\
\hline T1 & 0.31 & 4.66 & 0.00 & & & \\
\hline T2 & -0.21 & -3.21 & 0.00 & & & \\
\hline EE1 & 0.18 & 3.32 & 0.00 & & & \\
\hline EE2 & 0.48 & 8.28 & 0.00 & & & \\
\hline EE4 & 0.03 & 0.61 & 0.54 & & & \\
\hline OCB1 & -0.03 & -0.60 & 0.55 & & & \\
\hline OCB2 & 0.17 & 2.90 & 0.00 & & & \\
\hline OCB3 & 0.06 & 1.33 & 0.19 & & & \\
\hline
\end{tabular}

The $\mathrm{R}^{2}$ and Adjusted $\mathrm{R}^{2}$ value in the above table is 0.71 and 0.70 . Adjusted $\mathrm{R}^{2}$ value herein shows that about $70 \%$ of the variation in the value of organizational commitment level is being represented by the transactional leadership style, employee empowerment, and organizational citizenship behavior. F-value of 46.60 is greater than 1 which shows that more 
precision is derived by considering transactional leadership style, employee empowerment, and organizational citizenship behavior as independent variables. P-value of T1 (0.00), T2 (0.00), EE1 (0.00), EE2 (0.00) and OCB2 (0.00) is less than the significance level of the study i.e. 0.05. Thus, the null hypothesis of having no significant impact of antecedents on the organizational commitment level of employees is rejected. Coefficient value further depicts that with $1 \%$ increase in $\mathrm{T} 1$ (special recognition given to employees by leaders), EE1 (Employees feel capable), EE2 (self-assured employees), and OCB2 (suggestion offering by employees to one another) leads to rise in commitment level by $0.31 \%, 0.18 \%, 0.48 \%$, and $0.17 \%$ respectively. However, with increase in $\mathrm{T} 2$ (Leaders commends employees when done better job) by $1 \%$, there is decrease in commitment level by $0.21 \%$.

Hence, the above analysis of the effect shows that though transformational and transactional leadership style have significant influence on the organizational commitment level of employees but still majorly transformational leadership have more contribution in influencing the commitment. As there is more composition of transformational leadership (high adjusted $R^{2}$ ) in presence of employee empowerment and organizational citizenship behavior and even does have positive impact while one of the aspect of transactional leadership has negative influence; thus the infrastructure sector of large sized Indian organization using transformational leadership style tends to have better commitment of employees in working.

\section{CONCLUSIONS}

Infrastructure sector of India is an important constituent in the entire development of the economy. Although the $11^{\text {th }}$ five year plan there has been creation of opportunities to raise the investment level for the sector and have availability of facilities for fostering the growth but still the problem like uncertainties in regulatory approvals and land acquisition process, non-collaboration among stakeholders, scarcity of skilled labor, poor project management process, disparity in rural and urban development, and lack of facilities to fulfill consumer needshave contributed in having slow growth of the sector. Implementation of the effective leadership style is the means to overcome these challenges and have better development of the sector. Thus, this study aimed at assessing the different leadership style (transformational and transactional) and determining their contribution in influencing the organizational commitment level of employees. The primary data shows that organizations value the suggestions of employees and provide freedom to them but the final decision rests on the leaders. Examination of the effect of transformational and transactional leadership styles states that though both types of leaders have significant influence on the commitment level of employees but in order to have the better performance of the employees and effectively motivate them, infrastructure sector should use transformational leadership style. Herein, employees are involved in the decision making process, therefore their confidence and trust on the organization direct them towards better functioning. This would lead to overcoming the management issues of the sector and having sustainable contribution towards the development of Indian economy.

\section{REFERENCES}

1. Albdour, A. A., \& Altarawneh, |. 1. (2014).Employee Engagement and Organizational Commitment: Evidence from Jordan. International Journal of Business, 19(2).

2. Albion, M. J., \& Gagliardi, R. E. (2007). Study of Transformational Leadership, and Job Organisational Change Satisfaction. Toowoomba.

3. Al-Daibat, B. (2017). Impact of leadership styles in organizational commitment. International Journal of Business and Management Review, 5(5), 25-37. 
4. Allen, T. D., \& Rush, M. C. (1998). The effects of organisational citizenship behavior on performance judgments: A field of study and a laboratory of Applied experiment. JournalPsychology,83, 247-260.

5. Anderson, L. E. (2015). Relationship Between Leadership, Organizational Commitment, and Intent to Stay Among Junior Executives.

6. Anne Kariuki, \& Kellen Kiambati. (2017). Empowerment, Organizational Commitment, Organization Citizenship Behavior and Firm Performance. Management Studies, 5(4), 290-300. https://doi.org/10.17265/2328-2185/2017.04.003

7. Bass, M. B., \& Avolio, B. J. (1997). Fullrange leadership development. Manual for the Multifactor Leadership Questionnaire. California: Mind Garden.

8. Bushra, F., Usman, A., \& Naveed, A.(2011). Effect of Transformational Leadership on Employees 'Job Satisfaction and Organizational Commitment in Banking Sector ofLahore ( Pakistan ). Journal of Business \& Social Science, 2(18), 261268.http: //doi.org/10.5829/idosi.wasj.2013.26.07.1565

9. Caldwell, D. F., \& Chatman, J. A. (1990).Building organisational commitment: Amutlti form study. Journal of Occupational Psychology, 63, 245-26.

10. Cappelli, P., \& Rogovsky, N. (1998).Employee involvement and organisational citizenship: Implications for labor law reform and "lean production". Industrial and Labor Relations Review, 51, 633-654

11. Cohen, A. (1995). Some antecedents of employee commitment and_their influence on job performance: Amulti-foci study. South African Journal Business Management, 26, 45-135.

12. Ekene, C., \& Ugwunwanyi, A. (2016). Leadership and Economic Development in a Developing Economy: a Critical Look At the Nigeria'S' Experience. International Journal of Business and Management Review, 4(6), 105-114. www.eajournals.org

13. Fairholm, M. R. (2009). Leadership and Organizational Strategy. The Innovation Journal: The Public Sector Innovation Journal, 14.

14. Garg, A. K., \& Ramjee, D. (2013). The Relationship Between Leadership Styles And Employee Commitment At A Parastatal Company In South Africa. International Business \& Economics Research Journal, 12(11), 1411-1436.

15. Gita. (2014). Future of India - The Winning Leap. The Winning Leap, 1-148. https://www.pwc.in/assets/pdfs/future-ofindialfuture-of-india-the-winning-leap.pdf

16. G.Qaji, A., Proches, C., \& Green, P. (2016). Perceived impact of public sector leadership on road infrastructure service delivery. Investment Management and Financial Innovations, 13(3), 374-402. https://doi.org/10.21511/imfi.13(3-2).2016.12

17. Hanaysha, J. (2016). Examining the Effects of Employee Empowerment, Teamwork, and Employee Training on Organizational Commitment. Procedia - Social and Behavioral Sciences, 229, $298-306$. https://doi.org/10.1016/j.sbspro.2016.07.140

18. Hartog, D. N., \& Hartog, J. D. N. (1997).Transactional versus transformational leadership: An analysis of the MLQ. Journal of Occupation. Nal andOrganisational Psychology, 70.

19. Hater,: J. J., \& Bass, B. M. (1988).Evaluations and SubordinatesPerceptions of Transformational andTransactional Leadership. Journal of Applied Psychology, 19, 73-91.

20. Herscovitch, L., \& Meyer, J. P. (2002).Commitment to organizational change: Extension of a three-component model. Journal of Applied Psychology, 87, 447-487. 
21. Hunjra, A. J., Chani, M. |, \& Azam, M.(2010). Factors affecting jobsatisfaction of employees in Pakistanibanking sector. African Journal ofBusiness Management, 4, 2157-2163.

22. IBEF. (2013). the Indian Infrastructure Sector: Investments, Growth and Prospects (Issue January).

23. Insan, A. N., Astuti, E. S., Raharjo, K., \& Hamid, D. (2013). The Effect of Empowerment of the Organizational Commitment and the Job Satisfaction of the Employees of the National Electricity Company (Ltd.) in South Sulawesi Province Indonesia. Asian Transactions on Basic \& Applied Sciences, 03(04), 2221-4291. http://www.asiantransactions.org/Journals/Vol03Issue04/ATBAS/ATBAS-50301048.pdf

24. Irefin, P., \& Mechanic, M. A. (2014). Effect of Employee Commitment on Organizational Performance in CocaCola Nigeria Limited Maiduguri, Borno State Peace Irefin , 2 Mohammed Ali Mechanic. [OSR Journal of Humanities and Social Sciences, 19(3), 33-41.

25. Ironson, G. H., Smith, P. C., \& Brannick, M.T. (1989). Construction of a job in general scale: A comparison of global, composite, and specific measures. Journal of Applied Psychology, 74,193-200.

26. Jing-zhou, P., Xiao-xue, Z., \& Xia-qing, Z.(2010). The role of leadership between the employees and the organization - a bridge or a ravine? Anempirical study from China. Journal of Management and Marketing Research, 5(June), 1-14.

27. Kehinde, O., \& Banjo, H. (2014). A Test ofthe Impact of Leadership Styles on Employee Performance: A Study of Department of Petroleum Resources. International Journal of Management Sciences, 2, 149-160.

28. Khan, M. K., Tariq, A., Hamayoun, A. A., \& Bhutta, M. H. (2014). Enhancing Organizational Commitment Through Employee Empowerment - Empirical Evidence from Telecom Sector Employees. Middle-East Journal of Scientific Research, 21(1), 148157. https://doi.org/10.5829/idosi.mejsr.2014.21.01.21119

29. Kraus, A. J., \& Wilson, C. N. (2012).Leadership Development for Organizational. Success. Bowling Green.

30. Mester, C., Roodt, G., \& Kellerman, R.(2003). Leadership Style and Its Relation to Employee Attitudes and Behaviour. SA Journal of Industrial Psychology, 29(2), 72-82.http: //doi.org/10.4102/sajip.v29i2.100

31. Meyer, J. P., \& Allen, J. N. (1997).Commitment in the workplace. Thousand Oaks: Sage Publications.

32. MoSPI. (2019). Revamping Project Management - Assesment of infrastructure projects and corrective recommendations for performance improvement. A joint study conducted by PMI and KPMG in India on infrastructure projects in India, supported by Ministry of Statistics and P (Issue June). http://www.mospi.gov.in/sites/default/files/Kpmg1.pdf

33. Organ, D. W. (1988). Organisational citizenship behavior: The good soldier syndrome, Lexington: M A Lexington.

34. Pasmore, W. (2014). Developing a leadership strategy: A criticalingredient for organizational success. Centre for Creative Leadership.

35. Peris M.Koech \& Prof.G.S Namusonge(2012). The effect of Leadership Styles on Organizational Performance at State Corporations in Kenya. International Journal of Business and Commerce, Vol.2 ,No.1, 01-12

36. Schnake, M., \& Dumler, M. P. (1993). The relationship between "traditional" leadership, "super" leadership, and organisational citizenship behavior. Group: | and Organisational Management, 18, 352-365:

37. Shin, Y. (2013). The relationship between leadership styles, organizational commitment, and organizational outcome in Oklahoma's volunteer fire departments. 

their Impact on Organizational Commitment

38. Singh, V. (2017). An Investigation on the Relationship between Empowerment and Organizational Commitment (A Case Study of the Employees of IT Industry in NCR-Region). Professional Panorama: An International Journal of Applied Management \& Technology Volume:, IV(II).

39. Sohail, A., Unit, T. U., Khan, M. A., \& Campus, I. (2015). Impact of leadership style on Organization commitment. September 2011.

40. Solanki, T. P. (2016). Economic analysis of growth of infrastructure in Gujarat pre and post reform period. 83-112.

41. Wilson, M. A. (2001). Understanding organizational culture and the implications for corporate marketing. European Journal Marketing, 35, 353-367

42. Zaraket, W., Garios, R., \& Malek, L. A. (2018). The Impact of Employee Empowerment on the Organizational Commitment. International Journal of Human Resource Studies, 8(3), 284. https://doi.org/10.5296/ijhrs.v8i3.13528

43. George, Jithin Mathew, and Dave Hinkes. "The Best Leadership Style For Self-Managed Teams." International Journal of Business and General Management (IJBGM) 5.3 (2016):1-6

44. Gopal, R., and Rima Ghose Chowdhury. "Leadership styles and employee motivation: An empirical investigation in a leading oil company in India." IMPACT: International Journal of Research in Business Management (IMPACT: IJRBM) 2.5 (2014): 1-10.

45. Cipadung, AH Nasution, and Bandung Cibiru. "The Influence of the Regent Leadership Style on the Employee Performance in the Bandung Local Government." International Journal of Human Resource Management and Research (IJHRMR) 7.6 (2017):7-24.

46. Lokko, Francis Obodai, D. Min, and Christiana Naa Momo Lokko. "Leadership Styles Among Head Teachers as Predicted by Head Teachers and Teachers." BEST: International Journal of Humanities, Arts, Medicine and Sciences (BEST: IJHAMS) 4.6 (2016): 29-40. 

